The Polish Journal of the Arts and Culture. New Series 4

(2/2016): 27-46 [ARTYKUะ]

DOI: $10.4467 / 24506249$ PJ.16.009.6240

\title{
Nowy Jedwabny Szlak: nowa globalizacja?
}

\section{Adam NoBIs}

\section{Streszczenie}

Celem tekstu jest analiza globalnych konsekwencji Nowego Jedwabnego Szlaku. To nowy chiński projekt współpracy międzynarodowej, w realizację którego włączyło się wiele krajów. Analizuję zasięg geograficzny projektu oraz dziedziny, których dotyczy: ekonomię, politykę, kulturę. Wnioskiem jest stwierdzenie, że Nowy Jedwabny Szlak to nie tylko drogi, lecz także nowe wzorce i wartości relacji międzynarodowych oraz związany z nimi nowy porządek świata i nowa globalizacja, inne od tych, które są częścią dotychczasowej współczesności.

Słowa kluczowe: Nowy fedwabny Szlak, Chiny, kultura, globalizacja

Adam NoBis kulturoznawca, profesor Uniwersytetu Wrocławskiego, kieruje Pracownią Studiów Globalnych w Instytucie Kulturoznawstwa UWr, redaktor naczelny pisma „Kultura - Historia - Globalizacja" (www.khg.uni.wroc.pl). Zainteresowania badawcze to studia globalne. Najnowsza książka: Globalne procesy, globalne historie, globalny pieniqdz (2014).

E-MAIL: adam.nobis@uni.wroc.pl 


\section{Krótka historia Nowego Jedwabnego Szlaku}

Historia Nowego Jedwabnego Szlaku może się wydawać skromna w porównaniu z tym, który przez stulecia łączył odległe od siebie regiony Azji, Europy i Afryki. Historia tego nowego to zaledwie kilka ostatnich lat, ale i tak sprawia kłopot, by właściwie powiązać ze sobą projekty, wydarzenia i działania czy też dostrzec główne przyczyny i znaczenia. To jak szukanie głównego nurtu i źródła rzeki w zawiłym gąszczu dopływów. W naszej krótkiej historii pojawiają się różne miejsca, kraje, działania. Zacznijmy od 25 października 2008 roku, gdy z inicjatywy Turcji w Antalya odbyło się International Forum on the Role of Customs Administration on Facilitating and Promoting Trade among Silk Road Countries, na którym uczestniczące kraje podpisały wspólną deklarację dotyczącą ujednolicenia i uproszczenia procedur celnych i granicznych ${ }^{1}$. 11-12 listopada 2009 roku w Azerbejdżanie w Baku odbyło się kolejne spotkanie tego Forum, na którym przyjęto projekt „Caravanserai”, dotyczący rozwoju infrastruktury komunikacyjnej i handlowej łączącej kraje Azji Centralnej z portami Oceanu Indyjskiego². Rok później, 11-12 listopada 2010 roku w koreańskim Seulu odbyło się spotkanie G 20, na którym rozwój infrastruktury komunikacyjnej uznano za główny postulat dalszych wspólnych działań ${ }^{3}$. W 2011 roku w Nowym Jorku sekretarz stanu Hillary Clinton po powrocie z Azji Środkowej przedstawiła plan powojennej odbudowy Afganistanu poprzez rozwój infrastruktury łączącej ten kraj z Azją Centralną, Indiami i Pakistanem. Projekt określono jako „New Silk Road Initiative" 4 . W tym samym roku Asian Development Bank opublikował dokument „The New Silk Road”5. Do banku należy sześćdziesiąt siedem krajów, głównie z Azji, ale także spoza kontynentu, w tym także Stany Zjednoczone. W trakcie odbywającego się w Tokio w dniach 9-10 listopada 2012 roku „Symposion on a New Silk Road” reprezentujący Stany Zjednoczone Geoffrey Pyatt powiedział: „Nowy Jedwabny Szlak jest już w budowie”.

1 Antalya Declaration, International Forum on the Role of Customs Administration on Facilitating and Promoting Trade among Silk Road Countries, Antalya, Turcja, 25 X 2008 r., [www 01].

2 "Caravanserai" Project, [www 02].

3 J. Y. Lin, Industry Transfer to Africa Good for All, National School of Development, [www 03], s. 1.

4 V. Fedorenko, The New Silk Road Initiatives in Central Asia, „Rethinking Paper. Institute Washington DC" 10 (2013), [www 04], s. 4.

5 The New Silk Road. Ten Years of the Central Asia Regional Economic Cooperation Program, [www 05].

6 V. Fedorenko, op. cit., [www 04], s. 6. 
3 września 2012 roku w Urumqi, w północno-zachodnich Chinach, podczas „China-Eurasia Expo and Economic Development and Cooperation Forum" w obecności przedstawicieli pięćdziesięciu pięciu krajów premier Chińskiej Republiki Ludowej (ChRL) Jiabao Wen ${ }^{7}$ wygłosił odczyt zatytułowany „Towards New Glory of the Silk Road”. Rok później, 7 września 2013 roku, w trakcie pobytu w stolicy Kazachstanu - Astanie, przewodniczący ChRL Jinping Xi wygłosił odczyt na Uniwersytecie Nazarbajewa zatytułowany „Silk Road economic Belt”. Theresa Fallon zauważa, że nowy termin "economic belt” (ekonomiczny pas), określający powiązania między krajami Eurazji, wprowadzony został, by podkreślić odmienność nowej chińskiej propozycji od amerykańskiego projektu Hillary Clinton. Cytuje też chińskiego dyplomatę, który powiedział: „Gdy Stany Zjednoczone przedstawiły swoją propozycję, byliśmy zdruzgotani. Mieliśmy długie nieprzespane noce. Po dwóch latach przewodniczący Xi zaproponował wizję naszego nowego projektu Jedwabnego Szlaku"10. 2 października 2014 roku Jinping Xi w przemówieniu wygłoszonym w indonezyjskim parlamencie w Dżakarcie przedstawił kolejną koncepcję „Maritime Silk Road of the 21st Century”, która miałaby integrować Chiny morskimi połączeniami z krajami Azji PołudniowoWschodniej, Oceanu Indyjskiego, Zatoki Perskiej i Morza Śródziemnego ${ }^{11}$. Oba projekty w rozmaitych dokumentach i tekstach zaczęto określać wspólną nazwą „One Belt, One Road” (一带一路, yidai yilu), w skrócie OBOR ${ }^{12}$. Czy i czym chińska propozycja różni się od amerykańskiej? Helga Zepp-la Rouche pisze o chińskiej propozycji, że jest to: „Pierwszy krok w kierunku nowego ekonomicznego światowego porządku” ${ }^{13}$. O ile dotychczasowe projekty dotyczyły Azji Centralnej czy nawet Eurazji, chińska propozycja ma charakter globalny, a jednocześnie wpisuje się w te regionalne czy kontynentalne inicjatywy. O ile poprzednie miały charakter ekonomiczny, chiń-

7 Przy zapisie imion i nazwisk w swoim tekście przyjąłem konsekwentnie polski zwyczaj podawania najpierw imienia czy imion, a później nazwiska.

8 J. Wen, Towards New Glory of the Silk Road, [www 06].

9 J. Xi, Silk Road Economic Belt, [www 07].

${ }^{10}$ T. Fallon, The New Silk Road: Xi Finping's Grand Strategy for Euroasia, „American Foreign Policy Interests" 37 (2015), [www 08], s. 141.

${ }^{11} \mathrm{~J}$. Xi, Speech by Chinese President Xi finping to Indonesian Parliament, [www o9].

${ }^{12}$ D. Cohen, China's "Second Opening”: Grand Ambitions but a Long Road ahead, „China Analysis" June (2015), [www 10], s. 3.

${ }^{13}$ H. Zepp-La Rouche, The New Silk Road Leads to the Future Of Mankind!, [w:] The New Silk Road Becomes The World Land Bridge, „Executive Intelligence Review” April 10 (2015), [www 11], s. 3 . 
ska propozycja nie ogranicza się tylko do ekonomii. W 2014 roku Chiny utworzyły Silk Road Fund, z czterdziestoma miliardami dolarów przeznaczonymi na finansowanie nowej inicjatywy, i zainicjowały utworzenie nowego międzynarodowego banku - Asian Infrastructure Investment Bank ${ }^{14}$, do którego w trakcie następnych miesięcy akces zgłosiło pięćdziesiąt siedem krajów, między innymi: Australia, Brazylia, Egipt, Francja, Indie, Indonezja, Iran, Niemcy, Nowa Zelandia, Polska, Rosja, Turcja, Wielka Brytania, Włochy, Zjednoczone Emiraty Arabskie, ale nie Stany Zjednoczone czy Japonia ${ }^{15}$.

$\mathrm{Na}$ forum Ogólnochińskiego Zgromadzenia Przedstawicieli Ludowych w marcu 2015 roku minister spraw zagranicznych zadeklarował, że OBOR będzie priorytetem chińskiej dyplomacji ${ }^{16} .28$ marca 2015 roku Chiny opublikowały dokument „Vision and Actions on Jointly Building Silk Road Economic Belt and 21st Century Maritime Silk Road" ${ }^{17}$. Jego lektura przekonuje, że nowa jedwabna inicjatywa dotyczy nie tylko ekonomii.

\section{Drogi}

W dokumencie czytamy: „Ułatwienia połączeń są priorytetem dla realizacji Inicjatywy” ${ }^{18}$. Piotr Winnicki wyjaśnia, że oznacza to „budowę i modernizację infrastruktury transportowej - kolejowej i drogowej, portów lądowych i morskich oraz lotnisk, ale także ropociągów, gazociągów oraz sieci telekomunikacyjnej"19. François Godement zauważa, że Chiny w kolejnych latach zamierzają wydać na realizację projektu do 300 miliardów USD niezależnie od 890 miliardów inwestycji zaplanowanych przez China Development $\mathrm{Bank}^{20}$. Michael Billington określa to największym w historii rozwojem infra-

${ }^{14}$ M. Zhao, China's New Silk Road Initiative, „Istituto Affari Internazionali Working Papers” 15 (2015), s. 6.

${ }^{15}$ Asian Infrastructure Investment Bank, [www 12].

${ }^{16}$ T. Fallon, op. cit., [www 08], s. 141.

${ }^{17}$ Vision and Actions on Jointly Building Silk Road Economic Belt and 21st Century Maritime Silk Road, Issued by the National Development and Reform Commission, Ministry of Foreign Affairs, and Ministry of Commerce of the People's Republic of China, with State Council Authorization, [www 13].

${ }^{18}$ Ibidem, s. 4 .

${ }^{19}$ P. Winnicki, Nowy Jedwabny Szlak. Droga do budowy imperium, [www 14], s. 2.

${ }^{20}$ F. Godement, “One Belt, One Road”: China's Great Leap Outward, „China Analysis” June (2015), [www 15], s. 1. 
struktury w skali globalnej ${ }^{21}$. Na Nowy Jedwabny Szlak ma się składać pięć głównych dróg: trzy lądowe i dwie morskie ${ }^{22}$. Pierwsza: łącząca Chiny z Europą przez Azję Centralną i Rosję. Druga: przez Azję Centralną łącząca Chiny z Bliskim Wschodem. Trzecia: łącząca Chiny z Azją Południowo-Wschodnią, Południową i Oceanem Indyjskim. Czwarta: łącząca Chiny z Europą przez Ocean Indyjski. Piąta: łącząca Chiny z krajami południowego Pacyfiku. Helga Zepp-La Rouche dodaje do tego jeszcze dwie planowane chińskie inwestycje łączące Atlantyk z Pacyfikiem: alternatywny i większy od panamskiego kanał w Nikaragui oraz szybką kolej transamerykańską łączącą porty Peru i Brazylii. Wskazuje też na globalny charakter Nowego Jedwabnego Szlaku, którego celem jest nie tylko połączenie Chin ze światem zewnętrznym, lecz także „rozwój infrastrukturalnej komunikacji kontynentów Ziemi”23.

Marcin Kaczmarski za kluczowy dla projektu uznaje rozwój połączeń kolejowych między Chinami i Europą. Obecnie większość towarów z Chin trafia do Europy drogą morską przez Ocean Indyjski i Kanał Sueski, natomiast zaletą transportu kolejowego jest „kilkukrotnie krótszy czas w porównaniu z transportem morskim" (drogą morską 50-6o dni, drogą kolejową 12-16 dni $)^{24}$. Niektóre linie już działają: „pod koniec 2014 roku pociąg towarowy wyjechał z Yiwu, miasta na południe od Szanghaju, i jechał trzy tygodnie przez obszary Eurazji, aż dotarł do Madrytu"25. Chodzi o skrócenie czasu podróży poprzez modernizację starych i budowę nowych linii łączących Chiny między innymi z Azją Centralną, Rosją, Pakistanem, Iranem, Turcją. Projekty chińskie pokrywają się i uzupełniają z projektami Turcji, Rosji, Kazachstanu, Turkmenistanu, Uzbekistanu, a nawet Stanów Zjednoczonych ${ }^{26}$. Rozwój towarowych linii kolejowych ma służyć nie tylko eksportowi rezultatów chińskiej produkcji, lecz także importowi potrzebnych do tego surowców. ChRL w swoim rozwoju uzależniona jest od importu ropy i gazu, dlatego ważnym elementem Nowego Jedwabnego Szlaku są gazo- i ropociągi, a także nowe

${ }^{21}$ M. Billington, Xi Finping's New Silk Road: Reviving Confucian Culture, „Executive Intelligence Review" April 10 (2015), [www 16], s. 1.

${ }^{22}$ The Belt and Road Initiative, Hong Kong Trade Development Council Research, [www 17], s. 2-4.

${ }^{23}$ H. Zepp-La Rouche, op. cit., [www 11], s. 8.

${ }^{24}$ M. Kaczmarski, Nowy Jedwabny Szlak: uniwersalne narzędzie chińskiej polityki, Ośrodek Studiów Wschodnich, [www 18], s. 6.

${ }^{25}$ P. Vandenberg, K. Kikkawa, Global Value Chains along the New Silk Road, „Policy Brief ADBInstitute" 2, May (2015), s. 1.

${ }^{26}$ V. Fedorenko, op. cit., [www 04]. 
inwestycje w wydobycie surowców. Przykładem są projekty wydobycia gazu w Turkmenistanie czy Kazachstanie i gazociąg doprowadzający gaz do Chin albo ropociąg pozwalający na dostarczanie ropy naftowej z Kazachsta$\mathrm{nu}^{27}$. Badacze zwracają uwagę na chiński „dylemat Malakki” ${ }^{28}$. Prawie 85\% chińskiego importu dociera do kraju drogą morską przez cieśninę Malakka między Półwyspem Malajskim a Sumatrą, dlatego chińscy przywódcy martwią się wzrostem liczby pirackich napadów na statki w tym regionie czy ryzykiem blokady morskiej nałożonej na przykład przez Stany Zjednoczone. Planowane nowe połączenia lądowe Chin z Europą, a także z Pakistanem czy Birmą, mają na celu ominięcie tej cieśniny. Służą temu planowane linie kolejowe, gazo- i ropociągi, a także inwestycje portowe, jak na przykład port Gwadar, który Chiny planują wydzierżawić od Pakistanu.

\section{Jedwabny porządek}

Na obecnym etapie projekt Nowego Jedwabnego Szlaku bezpośrednio dotyczy sześćdziesięciu pięciu krajów reprezentujących 70\% ludności świata, 55\% jego produkcji i 75\% rozpoznanych złóż surowców ${ }^{29}$, zaś ChRL jest największym partnerem handlowym dla ponad stu dwudziestu krajów ${ }^{30}$. Chińscy politycy podkreślają, że projekt nadal jest otwarty dla wszystkich zainteresowanych państw, w związku z czym pojawiły się komentarze, że stanowi on chińskie ambicje zmiany globalnego porządku ${ }^{31}$, a „Nowy Jedwabny Szlak przeobrazi fundamentalnie nasz świat” ${ }^{22}$, albo że jest to po prostu „Nowy porządek świata”33, w którym Chiny będą „światowym centrum ekonomicznej

${ }^{27}$ Ibidem.

${ }^{28}$ J. Szczudlik-Tatar, China's New Silk Road Diplomacy, „Polski Instytut Spraw Międzynarodowych Policy Paper” 34 (82), (2013), s. 4-5; N. Rolland, China's New Silk Road, The National Bureau of Asian Research, [www 19], s. 3.

${ }^{29}$ D. Cohen, op. cit., [www 10], s. 4; Y. van der Leer, J. Yau, China's New Silk Route. The Long and Winding Road, „PwC's Growth Markets Centre” February (2016), s. 5.

${ }^{30}$ M. Zhao, op. cit., s. 5 .

${ }^{31}$ N. Chanda, The Silk Road - Old and New, ,The Times of India” October 16 (2015), [www 20], s. 2.

${ }^{32}$ A. Molavi, Five Ways the "New Silk Road" Could Transform the Global Economy, Credit Suisse, [www 21], s. 1.

33 The Silk Road, The New World Order and Eu-China Relations, Institute for European Studies, Vrije Universiteite Brussel, [www 22]. 
grawitacji”34. Chińscy autorzy wskazują na ekonomiczny charakter nowej inicjatywy. Yiping Huang zauważa, że przy pomocy projektu „Chiny, nowa potęga, wspierają międzynarodowy ład ekonomiczny (中国作为一个新兴大国 试图对国际经济秩序做出补充, Zhongguo zuo wei yige xinxing daguo shitu dui guoji jingji zhixu zuochu buchong)" 35 . Hao Su podkreśla, że dzięki projektowi ”Chiny stają się »dawcą, a nie biorcą《 (不是索取, 而是给予, bu shi suoqu, er shi jiyu) i pomagają w rozwoju biedniejszym krajom" ${ }^{36}$. Yongnian Zheng z Singapuru pisze, że zachodnie ekonomie „są odpowiedzialne za ekonomiczną i polityczną nierównowagę, która doprowadziła do globalnego finansowego kryzysu, a Chiny starają się przywrócić równowagę (再平衡, zai pingheng)”37.

Konsul ChRL w Petersburgu Ji Yan Chi wyjaśnia, że w chińskich propozycjach nie chodzi tylko o ekonomię, wymieniając pięć kluczowych sfer: polityczną, infrastrukturalną, handlową, finansową i społeczną ${ }^{38}$. Badacze, którzy dostrzegają, że chińskie propozycje poza ekonomią dotyczą także innych dziedzin życia, sięgają po określenie „światowy porządek Jedwabnego Szlaku” (Silk Road World Order) lub ,jedwabny porządek świata” (Silk World Order), albo jeszcze krócej: „jedwabny świat” (Silk World) ${ }^{39}$. Jurij Tawrowski zauważa, że nowe rozwiązania będą miały destrukcyjny wpływ na obecną globalizację, w której Stany Zjednoczone odgrywają kluczową rolę ${ }^{40}$ Inni piszą o nowej globalizacji lub chiglobalizacji, którą określają jako „globali-

${ }^{34}$ B. Simpfendorfer, One Belt, One Road Won't Move Dial on 2015 Growth, [w:] One Belt One Road. Assessing the Economic Impact of China's New Silk Road. Bloomberg BRIEF, [www 23], s. 5 .

35 D. Cohen, op. cit., [www 1o], s. 4. W tym: Y. Huang, Don't Let 'One Belt, One Road' Fall into the Trap of Japan's Overseas Investments.

${ }^{36}$ A. Bondaz, Rebalancing China's Geopolitics, „China Analysis” June (2015), [www 35], s. 6. W tym: H. Su, One Belt, One Road - Global Foundation of the Concept of a New Type of Great Powers.

${ }^{37}$ Ibidem, s. 7; Y. Zheng, Don't Let 'One Belt, One Road' Fall into the Trap of Japan's Overseas Investments, „Zhongguo Gaige Wang” 10 February (2015).

$3^{8}$ Я. Цзи, Это новая модель глобального управления, „Невское время”, [www 24], s. 3.

${ }^{39} \mathrm{P}$. Ni, The Underlying Philosophy and Impact of the New Silk Road World Order, „WPF Dialogue of Civilizations” 16 October (2015), [www 25]; M. D. Nazemroaya, The Silk World Order, „Modern Diplomacy” 15 July (2015), [www 26]; idem, Neither Greater Asia nor Greater Europe: America's «Chaos» versus a Silk World Order, „Strategic Culture Foundation Online Journal”, [www 27].

$4^{\circ 0}$ Ю.Тавровский, Новые мелодии «Шелкового пути», [www 28]. 
zację z chińskim charakterem" ${ }^{11}$ czy z chińską kulturą ${ }^{42}$. Mówienie o nowej globalizacji ma sens, jeśli pomyślimy o tym, że plany chińskie nie ograniczają się tylko do Starego Świata, lecz dotyczą bezpośrednio także obu Ameryk, gdzie planowane są dwie transamerykańskie inwestycje: kolej i kanał.

Ta nowa globalizacja byłaby konsekwencją i - paradoksalnie - częścią tego, co dzieje się w Chinach: „,jest ścisły związek między odrodzeniem chińskiego narodu i Chinami stającymi się światową potęgą. Gdyby Chiny nie stały się światową potęgą, odrodzenie chińskiego narodu byłoby niedokończone”43. Punkt widzenia Państwa Środka wyjaśniają tamtejsi autorzy: „By dołączyć do największych światowych potęg ekonomicznych, Chiny muszą bardziej skutecznie korzystać z rynku i surowców krajowych i zagranicznych. To jednak wymaga większej odpowiedzialności i większych wpływów globalnych”44, a także: „W Chinach nie ma wątpliwości. Muszą one zwiększyć swą międzynarodową odpowiedzialność. [...] Stało się to podstawą wielkiej strategii i polityki zagranicznej"45. Oficjalny państwowy dokument głosi: „Chiny są zobowiązane w ramach swoich możliwości do większej odpowiedzialności oraz wkładu w pokój i rozwój ludzkości" ${ }^{6}$. Alice Ekman pisze, że to wymaga „nowego modelu międzynarodowej kooperacji i globalnego zarządzania (global governance)" ${ }^{47}$. Nowy model nie oznacza tylko większego udziału Chin w zarządzaniu. Oznacza on nowe zasady, a to z kolei wymaga nowej, innej roli globalnej Chin. Huning Wang ponad dwadzieścia lat temu tak o tym pisał: „jeśli kraj ma podziwianą kulturę i ideologię, inne kraje mogą za nim podążyć" 48 . Zatem nie „twarde siły” ekonomii czy polityki, lecz kultura, określana jako „łagodna siła” (soft power), ma stanowić o wpływie kraju na globalne zarządzanie: „Łagodna siła jest obecnie gorącym tematem w Chinach. Zgodnie z dominującym poglądem kultura jest źródłem siły państwa" 49 .

${ }^{41}$ G. W. Doyle, Greater China In an Era of Globalization. Review, Global China Center, [www 29], s. 1.

${ }^{42}$ W. Jia, On the Discourse of Cultural China, John Benjamins Publishing Company, [www 30]. ${ }^{43} \mathrm{Z}$. Ye, Inside China's Grand Strategy: The Perspective from the People's Republic, University Press of Kentucky, Lexington 2010, s. 74; cyt. za: T. Fallon, op. cit., [www 08], s. 141.

${ }^{44}$ J. Y. Lin, China's Silk Road Vision, Project Sindicate, [www 31], s. 1.

${ }^{45}$ Y. Shi, The Roles China Ought to Play In the World, [www 32], s. 2.

${ }^{46}$ Vision and Actions..., [www 13], s. 2.

${ }^{47}$ A. Ekman, China: Reshaping the Global Order?, „Alert. European Union Institute for Security Studies" June (2015), s. 2.

${ }^{48}$ H. Wang, Culture as National Soft Power: Soft Power, ,Journal of Fudan University” March (1993); cyt. za: B. S. Glaser, M. E. Murphy, Soft Power with Chinese Characteristics. The Ongoing Debate, Center for Strategic and International Studies, [www 33] (dostęp: 22.02.2016), s. 12. ${ }^{49}$ Ibidem, s. 1. 
Jednak w Chinach wyraźnie dostrzegany jest brak równowagi w wymianie kulturowej ze światem, zwłaszcza z jego „zachodnią” częścią, dlatego ważnym celem polityki zagranicznej kraju stała się promocja jego kultury. Temu właśnie służyć ma „Rok Chin”, wydarzenia kulturalne, które odbywa się w różnych krajach od 2003 roku. W 2004 roku zaczęto organizować zagraniczne Instytuty Konfucjusza. W 2006 roku przyjęto pięcioletni plan kultury, który stał się istotnym składnikiem strategii go global ${ }^{50}$. W 2008 roku w Chinach odbyły się Igrzyska Olimpijskie, a dwa lata później w Szanghaju miała miejsce wystawa Expo. Telewizja chińska zaczęła nadawać programy w językach: angielskim, arabskim, francuskim, hiszpańskim, rosyjskim. To oczywiście tylko wybrane przykłady. Chińska polityka zagraniczna została oparta na „łagodnej sile” kultury, sama stając się jej przykładem.

Wieloletnie sprzeciwy Chin wobec użycia siły, nacisk na niezależność państw i ich terytorialną integralność, niewywieranie wpływu na sprawy wewnętrzne innych krajów, niezgoda na sankcje ekonomiczne i najnowsza koncepcja budowy harmonijnego świata odpowiada wielu krajom ${ }^{51}$.

Nowy Jedwabny Szlak i związany z nim nowy globalny porządek, czy nowa globalizacja, to przede wszystkim leżące u ich podstaw inne zasady, wzorce i wartości kulturowe. Nowy projekt ma zatem nie tylko charakter ekonomiczny i polityczny, lecz także kulturowy, a związane z nim treści kulturowe wymagają wyjaśnienia. Ji Yan Chi wymienia trzy zasady: „wspólne konsultacje, wspólny rozwój, wspólne korzyści” ${ }^{22}$. Qingguo Jia dodaje: „odłożyć spory i zająć się wspólnym rozwojem (搁置争议, 共同开发, gezhi zhengyi, gongtong kaifa)" ${ }^{53}$, a Yanchun Wang wyjaśnia, że Jedwabny Szlak oparty jest na „otwartej kooperacji (开放合作, kaifang hezuo)”54. Oznacza to dobrowolne uczestnictwo: nikt nie jest zmuszony i nikt nie jest wykluczony. $\mathrm{Z}$ zasad Nowego Jedwabnego Porządku wynikają jego własności. Mahdi Darius

$5^{0}$ Ibidem, s. 17; por. Outline of the National "11th Five Year Plan" Period Cultural Development Plan, [www 34].

${ }^{51}$ B. S. Glaser, M. E. Murphy, op. cit., [www 33], s. 18.

$5^{2}$ Я. Цзи, op. cit., [www 24], s. 3.

${ }^{53}$ Q. Jia, One Belt, One Road: Urgent Clarifications and Discussions of a Few Major Questions, „Renmin Luntan” 19 March (2015); cyt. za: D. Cohen, op. cit., [www 10], s. 4.

${ }^{54}$ Y. Wang, How to Deal with Geopolitical Risks During the Implementation of the One Belt One Road, „Gongshi Wang” 29 April (2015); cyt. za: A. Bondaz, op. cit., [www 35], s. 7. 
Nazemroaya pisze o multipolarności ${ }^{55}$, a Jurij Tawrowski o tym, że ma on charakter horyzontalny, a nie wertykalny:

Na spotkaniach w Ufie, Pekinie, Moskwie, Durbanie i New Delhi cegła po cegle budowane są podstawy nowego światowego porządku, który nie przewiduje przywództwa jakiegoś kraju lub grupy krajów. To niszczy finansowo-polityczną, wertykalną globalizację z dominującą rolą Stanów Zjednoczonych ${ }^{56}$.

Peimin Ni powołuje się na Tawrowskiego i dodaje: „W odróżnieniu od starego modelu, który oparty jest na sile militarnej i ekonomicznej, z najsilniejszymi na szczycie piramidy, nowy porządek świata jest multilateralny" ${ }^{\prime 7}$. Podaje przykład założonego przez Chiny banku AIIB, który jest ważnym elementem projektu. AIIB nie przewiduje prawa weta dla jakiegokolwiek kraju:

To wyraźny kontrast z tradycją Banku Światowego i MFW, gdzie Stany Zjednoczone mają jedyne prawo weta, posiadając mniej niż 20\% udziałów [...]. To interesujące, że kraj uważany za niedemokratyczny oręduje na rzecz globalnej demokracji, a kraj szczycący się swoją demokracją nękany jest wizerunkiem światowego hegemona ${ }^{5}$.

Różni komentatorzy już sam początek tworzenia nowego banku uznali za sukces, o którym świadczyć ma duża ilość krajów zgłaszających akces, w tym także spoza Azji. Wedle She Jianguang i Shui Shangnan „sukces banku to efekt charakteru tej instytucji, multilateralnego banku rozwoju nowego cza$\mathrm{su}$ (新时代多边开发银行, xin shidai duobian kaifa yinhang)" 59 . Xiaoke Meng kontrastuje nowatorstwo zasad nowego banku z przestarzałymi instytucjami międzynarodowymi, będącymi częściami porządku Bretton Woods ustanowionego ponad siedemdziesiąt lat temu, gdy „Stany Zjednoczone wytwarzały prawie $50 \%$ światowej produkcji i posiadały $70 \%$ światowych zapasów złota"6o.

${ }_{55}$ M. Nazemroaya, Neither Greater Asia..., [www 27], s. 1.

${ }^{56}$ Ю. Тавровский, op. cit., [www 28], s. 1.

${ }^{57}$ P. Ni, op. cit., [www 25], s. 4 .

${ }^{5}$ Ibidem, s. 3.

${ }^{59}$ A. Kratz, China's AIIB: A Triumph in Public Diplomacy, „China Analysis” June (2015), [www 36], s. 14 .

${ }^{60}$ Ibidem; por. X. Meng, Why have European powers embraced the AIIB one after another?, „Zhongguo Qingnian Bao - China Youth daily”, 25 March (2015). 
W Vision and Actions mowa jest o „multipolarnym świecie”, „kulturowej różnorodności”, „wzmacnianiu wymiany kulturowej, zachęcaniu różnych cywilizacji do uczenia się od siebie i wspólnego rozwoju, promocji wzajemnego rozumienia, pokoju i przyjaźni między ludźmi wszystkich krajów" ${ }^{\text {. }}$. Czytamy także:

Inicjatywa opiera się na harmonii i inkluzyjności. Postuluje tolerancję między cywilizacjami, respektowanie dróg i sposobów rozwoju wybranych przez różne kraje, wspiera dialog między różnymi cywilizacjami na zasadach poszukiwania tego, co wspólne, przy zachowaniu różnic ${ }^{62}$.

Jednocześnie na różne sposoby podkreślany jest uniwersalizm nowej inicjatywy. Uniwersalny charakter ma mieć już samo dziedzictwo starego Jedwabnego Szlaku: „Symbolizując komunikację i kooperację między Wschodem i Zachodem, Jedwabny Szlak jest historycznym i kulturowym dziedzictwem wszystkich krajów świata" ${ }^{63}$. Dalej dokument powołuje się na pięć podstawowych zasad Karty Narodów Zjednoczonych: „,wzajemne poszanowanie suwerenności terytorialnej, powstrzymanie się od agresji, niewywieranie wpływu na sprawy wewnętrzne, równość i wzajemność korzyści, pokojowe współistnienie” ${ }^{64}$. Nake Kamrany pisze krótko: „To chiński Nowy Porządek Świata

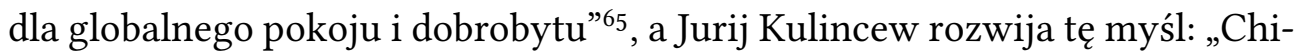
ny gotowe są wnieść większy wkład w rozwój całej ludzkości. [...] Strukturalną podstawą chińskiego projektu jest przyjęcie takiej formuły współpracy, w której korzystają wszyscy uczestnicy" ${ }^{66}$. Yiwei Wang pisze, że celem jest budowanie „wspólnoty interesów i bezpieczeństwa (利益+安全共同体, liyi+ anquan gongtongti)" ${ }^{\prime 67}$. Wskazuje on na to, co wspólne, podczas gdy Jun Wang pisze o różnicach: „Chiny powinny szukać tego, co wspólne, pomimo różnic (求同存异, qiutongcunyi) "68. Helga Zepp-La Rouche stwierdza, że uniwersa-

${ }^{61}$ Vision and Actions..., [www 13], s. 3.

${ }^{62}$ Ibidem, s. 3.

${ }^{63}$ Ibidem, s. 1.

${ }^{64}$ Ibidem, s. 3.

${ }^{65}$ N. Kamrany, China's New World Order: Sharing Global Prosperity Through Connectivity of the Silk Route Countries, „The World Post”, [www 37], s. 1.

${ }^{66} Ю$. Кулинцев, «Один пояс - один путь»: инициатива с китайской спецификой, [www 38], s. 1.

${ }^{67}$ Y. Wang, How to Deal..., za: A. Bondaz, op. cit., [www 35], s. 6.

${ }^{68}$ J. Wang, How Can the AIIB Still Succeed?, „Caixin Zhoukan - Caixin Weekly”, 6 April (2015); cyt. za: A. Kratz, op. cit., [www 36], s. 16. 
lizm projektu nie przekreśla tych różnic, a nowy model kooperacji między narodami oznacza, że „muszą one respektować różne rozwoje, historie, kultury i społeczne systemy, a przede wszystkim narodową suwerenność. To idea jedności w wielości, o której pisał Mikołaj z Kuzy"69.

Peimin Ni także wskazuje na filozoficzne podstawy projektu, ale przedstawia je inaczej. Przywołuje dwa określenia stosowane często przez przewodniczącego ChRL Xi: „wspólnotę przeznaczenia” (命运共同体, mingyun gongtongti) oraz „współpracę i wspólną pomyślność” (合作共赢, hezuogongyin) i wyjaśnia następująco - pierwsze oznacza, że

[...] świat jest wspólnotą, w której nasze przeznaczenie dzielimy z innymi. [...] Jeśli zaś jesteśmy wspólnotą przeznaczenia, to musimy ze sobą współpracować. [...] Ten filozoficzny pogląd jest głęboko zakorzeniony w tradycyjnej chińskiej kulturze. [...] W tradycji Konfucjusza znane jest rozumienie tianxia 天下, „wszystko pod niebem” jako wspólnoty przeznaczenia. Współczesny chiński filozof polityki Zhao Tingyang zauważa, że tianxia reprezentuje filozofię całkowicie odmienną od tej leżącej u podstaw państwa narodowego. Tianxia to postrzeganie wzajemnych powiązań między wszystkim pod niebem. [...] Dzięki pojęciu tianxia jako globalnej wspólnoty wspólnego przeznaczenia możliwe staje się przezwyciężenie ograniczeń myślenia w kategoriach państwa narodowego, a Chiny mogą stać się główną siłą kierującą świat ku pokojowemu porządkowi ${ }^{70}$.

Ni wskazuje także na konfucjańskie określenie Wielkiej Harmonii (大同, $d a-$ tong), o którym Michael Billington pisze: „Koncepcja harmonii wprowadzona przez Konfucjusza zainspirowała Chiny do zaproponowania współpracy opartej na zasadzie wspólnych korzyści wszystkich narodów uczestniczących w wielkim infrastrukturalnym projekcie"71.

Projekt Nowego Jedwabnego Szlaku czy Jedwabnego Porządku Świata dotyczy ekonomii, polityki i kultury. W tym ostatnim przypadku chodzi o leżące u jego podstaw i lansowane przezeń specyficzne treści kulturowe, kształtujące relacje międzynarodowe i związany z nimi porządek globalny. Są to wartości, normy, wzorce i idee inne od dotychczas dominujących.

\footnotetext{
${ }^{69}$ H. Zepp-LaRouche, op. cit., [www 11], s. 10.

${ }^{70}$ P. Ni, op. cit., [www 25], s. $4^{-6 .}$

${ }^{71}$ M. Billington, op. cit., [www 16], s. 1.
} 


\section{Jedwabne dylematy i pytania}

Nowy Jedwabny Szlak to oczywiście nie tylko drogi. To także wspomniane wyżej kulturowe treści, związane z wartościami i postawami, które kreują nowy światowy porządek. Są one inną interpretacją treści współtworzących obecną globalizację, dlatego warto dostrzec odmienność globalnego charakteru projektu Nowego Jedwabnego Porządku. Rok 2049, setna rocznica powstania Chińskiej Republiki Ludowej, jest podawany jako czas ukończenia projektu $^{72}$. Niektóre jego elementy są już opracowane, inne są w trakcie realizacji, jeszcze inne istnieją w postaci planów, umów między państwami, przedsiębiorstwami, instytucjami. Podkreślana otwartość projektu oznacza, że może on zostać poszerzony o nieplanowane wcześniej realizacje. Wyraźne są także pewne dylematy, będące jego integralną częścią. Ograniczę się do wskazania trzech. Pierwszy dylemat dotyczy relacji ze Stanami Zjednoczonymi. W dokumentach, przemówieniach i na konferencjach często mówi się o tym, że projekt nie jest skierowany przeciwko jakiemukolwiek państwu. A jednak jego multipolarność jest wyraźnym wyzwaniem wobec wyjątkowej pozycji Stanów Zjednoczonych we współczesnym świecie. Jak Chiny będą kształtować swoje relacje z tym krajem? Jak Stany Zjednoczone będą kształtowały relacje z inicjatywą o globalnych ambicjach, konsekwencjach i charakterze? Drugi dylemat to sprawa „modelu chińskiego”. Badacze podkreślają silne związki między projektem i sytuacją wewnętrzną Chin. Jest on konsekwencją i elementem przeobrażeń, jakim podlega Państwo Środka, a skoro tak, to czy nie jest realizacją kształtujących ten kraj wartości i wzorców? Jedni wskazują na konfucjanizm, inni na socjalistyczne wartości ${ }^{73}$. Czy to oznacza globalizację z chińskim charakterem? Czy to, co specyficznie chińskie, może mieć zastosowanie w przypadku innych społeczeństw? I czy nie jest to sprzeczne z zasadą multipolarności projektu? Trzeci dylemat to relacja multipolarność - uniwersalność. Czy uniwersalność jest do pogodzenia z multipolarnością? Czy uniwersalność rozumiana jako wspólnota przeznaczenia pod niebem nie oznacza podważenia roszczeń co do suwerenności państwowej, a tym samym multipolarności? Czy konsekwentna multipolarność nie oznacza różnych uniwersalizmów, opartych na odmiennych wzorcach i wartościach?

Projekt prowokuje do stawiania dalszych pytań i obawiam się, że ich lista ma charakter równie otwarty i rozległy jak on sam. Czy Chińska Republika

\footnotetext{
${ }^{72}$ A. Ekman, op. cit., s. 2.

${ }^{73}$ B. S. Glaser, M. E. Murphy, op. cit., [www 33], s. 22.
} 
Ludowa przetrwa do 2049 roku? To oczywiście przypomina inne pytanie: „Czy Związek Radziecki przetrwa do 1984 roku?” - taki był tytuł eseju Andrieja Amalrika z 1969 roku. Na to pierwsze pytanie nie znam odpowiedzi, ale nie wątpię, że Chiny nadal będą częścią świata. Jaką rolę będą w nim odgrywać i jaki będzie on miał charakter? A może zamiast pytać lepiej uważnie obserwować to, co dzieje się współcześnie, kształtując, czyli przekształcając świat, w którym żyjemy?

\section{Bibliografia}

1. Antalya Declaration, International Forum on the Role of Customs Administration on Facilitating and Promoting Trade among Silk Road Countries, Antalya, Turcja, 25 X 2008 r., [www 01] (dostęp: 11.03.2016).

2. Asian Infrastructure Investment Bank, [www 12] (dostęp: 11.03.2016).

3. Billington M., Xi finping's New Silk Road: Reviving Confucian Cultu$r e$, „Executive Intelligence Review” April 10 (2015), [www 16] (dostęp: 22.02.2016).

4. Bondaz A., Rebalancing China’s Geopolitics, „China Analysis” June (2015), [www 35] (dostęp: 18.02.2016).

5. "Caravanserai" Project, [www 02] (dostęp: 11.03.2016).

6. Chanda N., The Silk Road - Old and New, „The Times of India” October 16 (2015), [www 20] (dostęp: 16.03.2016).

7. CoHen D., China's “Second Opening”: Grand Ambitions but a Long Road Ahead, „China Analysis” June (2015), [www 10] (dostęp: 18.02.2016).

8. Doyle G. W., Greater China In an Era of Globalization. Review, Global China Center, [www 29] (dostęp: 16.03.2016).

9. Ekman A., China: Reshaping the Global Order?, „Alert. European Union Institute for Security Studies" June (2015), s. 1-2.

10. Fallon T., The New Silk Road: Xi Finping's Grand Strategy for Euroasia, „American Foreign Policy Interests” 37 (2015), [www o8] (dostęp: 18.02.2016).

11. Fedorenko V., The New Silk Road Initiatives in Central Asia, „Rethinking Paper. Institute Washington DC” 10 (2013), [www 04] (dostęp: 18 II 2016).

12. Glaser B. S., Murphy M. E., Soft Power with Chinese Characteristics. The Ongoing Debate, Center for Strategic and International Studies, [www 33] (dostęp: 22.02.2016). 
13. Godement F., “One Belt, One Road”: China's Great Leap Outward, „China Analysis" June (2015), [www 15] (dostęp: 18.02.2016).

14. Huang Y., Don't Let 'One Belt, One Road' Fall into the Trap of Japan's Overseas Investments, „Zhongguo Gaige Wang” 10 February (2015).

15. Jia Q., One Belt, One Road: Urgent Clarifications and Discussions of a Few Major Questions, „Renmin Luntan” 19 March (2015).

16. JiA W., On the Discourse of Cultural China, John Benjamins Publishing Company, [www 30] (dostęp: 16.03.2016).

17. Kaczmarski M., Nowy Jedwabny Szlak: uniwersalne narzędzie chińskiej polityki, Ośrodek Studiów Wschodnich, [www 18] (dostęp: 15.02.2016).

18. Kamrany N., China's New World Order: Sharing Global Prosperity Through Connectivity of the Silk Route Countries, „The World Post”, [www 37] (dostęp: 18.02.2016).

19. Kratz A., China's AIIB: A Triumph in Public Diplomacy, „China Analysis" June (2015), [www 36] (dostęp: 18.02.2016).

20. VAN Der Leer Y., YAu J., China's New Silk Route. The Long and Winding Road, „PwC's Growth Markets Centre” February (2016), s. 1-7.

21. Lin J. Y., China's Silk Road Vision, Project Sindicate, [www 31] (dostęp: 18.02.2016).

22. Lin J. Y., Industry Transfer to Africa Good for All, National School of Development, [www 03] (dostęp: 11.03.2016).

23. Meng X., Why have European powers embraced the AIIB one after another?, „Zhongguo Qingnian Bao - China Youth daily”, 25 March (2015).

24. Molavi A., Five Ways the "New Silk Road" Could Transform the Global Economy, Credit Suisse, [www 21] (dostęp: 18.02.2016).

25. Nazemroaya M. D, Neither Greater Asia nor Greater Europe: America's «Chaos» versus a Silk World Order, „Strategic Culture Foundation Online Journal”, [www 27] (dostęp: 22.02.2016).

26. Nazemroaya M. D., The Silk World Order, „Modern Diplomacy” 15 July (2015), [www 26] (dostęp: 22.02.2016).

27. Ni P., The Underlying Philosophy and Impact of the New Silk Road World Order, „WPF Dialogue of Civilizations” 16 October (2015), [www 25] (dostęp: 18.02.2016).

28. Outline of the National "11th Five Year Plan" Period Cultural Development Plan, [www 34] (dostęp: 17.03.2016).

29. Rolland N., China's New Silk Road, The National Bureau of Asian Research, [www 19] (dostęp: 18.02.2016). 
30. SHi Y., The Roles China Ought to Play In the World, [www 32] (dostęp: 22.02.2016).

31. Simpfendorfer B., One Belt, One Road Won't Move Dial on 2015 Growth [w:] One Belt One Road. Assessing the Economic Impact of China's New Silk Road. Bloomberg BRIEF, [www 23] (dostęp: 18.02.2016).

32. Su H., One Belt, One Road - Global Foundation of the Concept of a New Type of Great Powers, „Shenzen Shangbao - Shenzhen Economic Daily” 15 April (2015).

33. Szczudlik-Tatar J., China’s New Silk Road Diplomacy, „Polski Instytut Spraw Międzynarodowych Policy Paper" 34 (82), (2013), s. 1-8.

34. The Belt and Road Initiative, Hong Kong Trade Development Council Research, [www 17] (dostęp: 22.02.2016).

35. The New Silk Road. Ten Years of the Central Asia Regional Economic Cooperation Program, [www 05] (dostęp: 18.02.2016).

36. The Silk Road, The New World Order and Eu-China Relations, Institute for European Studies, Vrije Universiteite Brussel, [www 22] (dostęp: 18.02.2016).

37. Vandenberg P., Kiknawa K., Global Value Chains along the New Silk Road, „Policy Brief ADBInstitute” 2, May (2015), s. 1-6.

38. Vision and Actions on fointly Building Silk Road Economic Belt and 21st Century Maritime Silk Road, Issued by the National Development and Reform Commission, Ministry of Foreign Affairs, and Ministry of Commerce of the People's Republic of China, with State Council Authorization, [www 13] (dostęp: 22.02.2016).

39. WAng H., Culture as National Soft Power: Soft Power, „Journal of Fudan University" March (1993).

40. Wang J., How Can the AIIB Still Succeed?, „Caixin Zhoukan - Caixin Weekly", 6 April (2015).

41. Wang Y., How to Deal with Geopolitical Risks During the Implementation of the One Belt One Road, „Gongshi Wang” 29 April (2015).

42. Wen J., Towards New Glory of the Silk Road, [www o6] (dostęp: 11.03.2016).

43. Winnicki P., Nowy Jedwabny Szlak. Droga do budowy imperium, [www 14] (dostęp: 18.02.2016).

44. XI J., Silk Road Economic Belt, [www 07] (dostęp: 11.03.2016).

45. XI J., Speech by Chinese President Xi finping to Indonesian Parliament, [www 09] (dostęp: 11.03.2016). 
46. Ye Z., Inside China's Grand Strategy: The Perspective from the People's Republic, University Press of Kentucky, Lexington 2010.

47. Zepp-La Rouche H., The New Silk Road Leads to the Future Of Mankind! [w:] The New Silk Road Becomes The World Land Bridge, „Executive Intelligence Review” April 10 (2015), [www 11] (dostęp: 17.02.2016).

48. Zнао M., China's New Silk Road Initiative, „Istituto Affari Internazionali Working Papers" 15 (2015), s. 1-12.

49. Zheng Y., The "One Belt, One Road" Strategy Helps the World Economy Rebalance, „Lianhe Zaobao - Oriental Morning Post” 8 January (2015).

50. Кулинцев Ю., «Один пояс - один путь»: инициатива с китайской спецификой, [www 38] (dostęp: 22.02.2016).

51. Тавровский Ю., Новые мелодии «Шелкового пути», [www 28] (dostęp: 22.02.2016).

52. Цзи Я., Это новая модель глобального управления, „Невское время”, [www 24] (dostęp: 22.02.2016).

\section{Wykorzystane źródła internetowe:}

[www 01] http://www.iru.org/cms-filesystem-action?file=webnews2008/ Antalya-Declaration2008.pdf (dostęp: 11.03.2016)

[www 02] http://abc.az/eng/news/66776.html (dostęp: 11.03.2016)

[www 03] http://en.nsd.edu.cn/article.asp?articleid=7477 (dostęp: 11.03.2016) [www 04] http://www.rethinkinstitute.org/wp-content/uploads/2013/11/ Fedorenko-The-New-Silk-Road.pdf (dostęp: 18 II 2016)

[www 05] http://www.adb.org/sites/default/files/publication/29389/newsilk-road.pdf (dostęp: 18.02.2016)

[www 06] http://news.xinhuanet.com/english/china/2012-09/03/c_ 131823021.htm (dostęp: 11.03.2016)

[www 07] http://english.cntv.cn/program/china24/20130907/103428.shtml (dostęp: 11.03.2016)

[www 08] http://www.ou.edu/uschina/texts/Fallon.2015.AFPI.New_Silk_ Road.pdf (dostęp: 18.02.2016)

[www 09] http://www.asean-china-center.org/english/2013-10/03/c_ 133062675.htm (dostęp: 11.03.2016)

[www 10] http://www.ecfr.eu/page/-/China_analysis_belt_road.pdf (dostęp: 18.02.2016)

[www 11] http://larouchepub.com/hzl/2014/4134silk_rd_future.html (dostęp: 17.02.2016) 
[www 13] http://en.ndrc.gov.cn/newsrelease/201503/t20150330_669367.html (dostęp: 22.02.2016)

[www 14] http://biznes.pl/magazyny/handel/nowy-jedwabny-szlak-drogado-budowy-imperium/cct76t (dostęp: 18.02.2016)

[www 15] http://www.ecfr.eu/publications/summary/one_belt_one_road_ chinas_great_leap_outward3055 (dostęp: 18.02.2016)

[www 16] http://larouchepub.com/other/2015/4215xi_confucian_culture.html (dostęp: 22.02.2016)

[www 17] http://china-trade-research.hktdc.com/business-news/article/OneBelt-One-Road/The-Belt-and-Road-Initiative/obor/en/1/1Xoooooo/

1XoA36B7.htm (dostęp: 22.02.2016)

[www 18] http://www.osw.waw.pl/pl/publikacje/komentarze-osw/2015-02-10/ nowy-jedwabny-szlak-uniwersalne-narzedzie-chinskiej-polityki (dostęp:

15.02.2016)

[www 19] http://nbr.org/research/activity.aspx?id=531 (dostęp: 18.02.2016)

[www 2o] http://blogs.timesofindia.indiatimes.com/toi-edit-page/the-silk-roadold-and-new/ (dostęp: 16.03.2016)

[www 21] https://www.credit-suisse.com/us/en/news-and-expertise/economy/ articles/news-and-expertise/2015/11/en/five-ways-the-new-silk-road-couldtransform-the-global-economy.html (dostęp: 18.02.2016)

[www 22] http://www.ies.be/node/3372 (dostęp: 18.02.2016)

[www 23] http://www.bloombergbriefs.com/content/uploads/sites/2/2015/o7/

SC_062615-OBOR.pdf (dostęp: 18.02.2016)

[www 24] http://www.nvspb.ru/tops/eto-novaya-model-globalnogo-

upravleniya-57593/?version=print (dostęp: 22.02.2016)

[www 25] http://wpfdc.org/blog/politics/19534-the-underlying-philosophyand-impact-of-the-new-silk-road-world-order (dostęp: 18.02.2016)

[www 26] http://moderndiplomacy.eu/index.php?option=com_k2\&view=item\&i $\mathrm{d}=847$ :the-silk-world-order\&Itemid $=490($ dostęp: 22.02 .2016$)$

[www 27] http://www.strategic-culture.org/news/2015/07/03/neither-greaterasia-nor-greater-europe-america-chaos-versus-silk-world-order.html (dostęp: 22.02.2016)

[www 28] http://russian.people.com.cn/n/2015/o716/c95181-8921285.html (dostęp: 22.02.2016)

[www 29] http://www.globalchinacenter.org/analysis/chinese-society-politics/ globalization-and-chinese-christianity.php (dostęp: 16.03.2016)

[www 30] https://benjamins.com/\#catalog/journals/japc.21.2.01jia/details (dostęp: 16.03.2016) 
[www 31] https://www.project-syndicate.org/commentary/china-maritimesilk-road-economic-belt-by-justin-yifu-lin-2016-01?barrier=true (dostęp: 18.02.2016)

[www 32] http://www.brookings.edu//media/Events/2011/5/19-us-china/ 0519_yinhong_presentation.PDF (dostęp: 22.02.2016) [www 33] http://csis.org/files/media/csis/pubs/o90310_chinesesoftpower chap2.pdf (dostęp: 22.02.2016)

[www 34] https://chinacopyrightandmedia.wordpress.com/2006/o9/13/ outline-of-the-national-11 th-five-year-plan-period-cultural-developmentplan/ (dostęp: 17.03.2016)

[www 35] http://www.ecfr.eu/page/-/China_analysis_belt_road.pdf (dostęp: 18.02.2016)

[www 36] http://www.ecfr.eu/page/-/China_analysis_belt_road.pdf (dostęp: 18.02.2016)

[www 37] http://www.huffingtonpost.com/nake-m-kamrany/chinas-newworld-order-sh_b_7490142.html (dostęp: 18.02.2016)

[www 38] http://russiancouncil.ru/blogs/riacexperts/?id_4=1868

(dostęp: 22.02.2016) 


\title{
Abstract, keywords, about the author
}

\begin{abstract}
NEW SILK ROUTE: NEW GLOBALISATION?

The aim of the paper is to evaluate the global consequences of the New Silk Road. This is a new Chinese project involving international cooperation, the implementation of which included a number of countries. I analyse the geographical scope of the project and the areas concerned: economics, politics, culture. The conclusion is that the New Silk Road is not only about transportation routes but also the new patterns and values of international relations and the related new world order as well as the new globalisation besides those elements that are part of the present.
\end{abstract}

Keywords: New Silk Road, China, culture, globalisation

Adam NoBIs professor at Wrocław University, manager of Global Studies Laboratory, editor in chief of "Culture-History-Globalization" (www.khg.uni.wroc.pl). Research interests: global studies. New book: "Global processes, global histories, global money" 2014. E-MAIL: adam.nobis@uni.wroc.pl 